
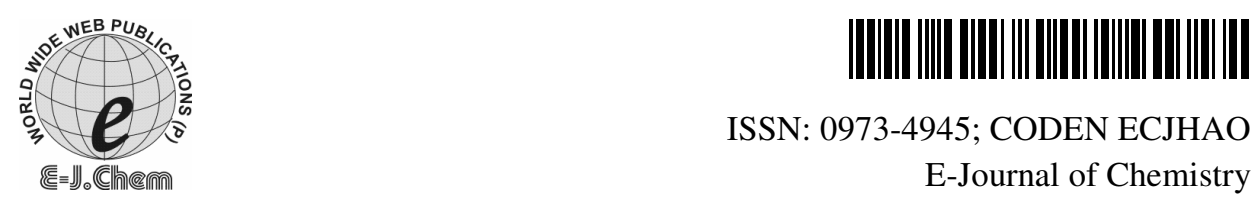

ISSN: 0973-4945; CODEN ECJHAO

E-Journal of Chemistry

http://www.e-journals.net

2011, 8(3), 1246-1249

\title{
Thermal Properties of Some Organic Liquids Using Ultrasonic Velocity Measurements
}

\author{
P.RAMADOSS* and N.BUVANESWARI \\ Department of Physics, Government Arts College \\ Tiruvannamalai-606 603, Tamilnadu, India \\ dossrpg@yahoo.co.in
}

Received 16 September 2010; Revised 24 November 2010; Accepted 18 December 2010

\begin{abstract}
Debye temperature and thermal relaxation time has been calculated in normal and boiling temperature. Using thermal relaxation time, the heat of fusion has been calculated for nineteen organic liquids and the results throw light on the method of calculating heat of fusion.
\end{abstract}

Keyword: Debye temperature, Heat of fusion, Ultrasonic velocity, Thermal properties

\section{Introduction}

Physical, chemical and thermo acoustical parameters of liquids, liquid mixtures, polar and non polar solutions and liquefied gases are very important for industrial applications. Ultrasonic velocity measurements has been carried out to bring out physical, chemical and thermal properties of liquids, liquid mixtures, polar and non polar solutions using its allied parameters like density, viscosity, surface tension etc., Ultrasonic measurement is one of the easiest method to calculate the properties of liquids like compressibility, internal pressure and so on ${ }^{1-7}$.

In the present work, an attempt is made to calculate Debye temperature and relaxation time of liquid at normal and boiling temperature. Using relaxation time, heat and fusion has been calculated for the 19 organic liquids such as methanol, acetic acid, ethylene glycol, chloroform, heptane, octane, phenol, acetone, pentane, ethanol, benzene, toluene, glycerin, butanol, pentanol, methyl propanol, hexanol, propanol and heptanol.

\section{Theory and calculations}

Ultrasonic velocity and applied parameters are used to calculate Debye temperature as ${ }^{8}$

Where,

$$
\Theta=\left(\mathrm{h} / \mathrm{k}_{\mathrm{B}}\right)\left\{[9 \mathrm{~N} / 4 \pi \mathrm{V}] /\left[\left(1 / \mathrm{C}_{\mathrm{l}}^{3}\right)+\left(2 / \mathrm{C}_{\mathrm{t}}^{3}\right)\right]\right\}^{1 / 3}
$$

$\mathrm{h}$ is the Planck's constant in Js,

$\mathrm{k}_{\mathrm{B}}$ is the Boltzmann's constant in $\mathrm{J} / \mathrm{K}$, 
$\mathrm{N}$ is the Avagadro number in $\mathrm{kg} / \mathrm{mol}$,

$\mathrm{V}$ is the volume of the liquid $\mathrm{m}^{3}$.

$$
\begin{aligned}
& \frac{1}{C_{1}^{3}}=\left[\frac{1+\sigma}{3(1-2 \sigma)}\right]^{3 / 2}\left(\rho \beta_{T}\right)^{3 / 2} \\
& \frac{1}{C_{1}^{2}}=\left[\frac{2(2+\sigma)}{3(1-2 \sigma)}\right]^{3 / 2}\left(\rho \beta_{T}\right)^{3 / 2}
\end{aligned}
$$

Where,

$\mathrm{C}_{1}$ is velocity of longitudinal waves in $\mathrm{m} / \mathrm{s}$,

$\mathrm{C}_{\mathrm{t}}$ is velocity of transverse waves in $\mathrm{m} / \mathrm{s}$,

$\rho$ is the density of liquid in $\mathrm{kg} / \mathrm{m}^{3}$

$$
\begin{aligned}
& \sigma=(3 \mathrm{~A}-2) /(6 \mathrm{~A}+2) \\
& \mathrm{A}=4 / 3(1 / \mathrm{v}) \\
& \beta_{\mathrm{T}}=\beta \mathrm{s}=1 / \mathrm{u}^{2} \rho
\end{aligned}
$$

Where,

$\beta_{\mathrm{T}}$ is adiabatic compressibility of liquid in $\mathrm{m}^{2} / \mathrm{N}$

$\beta \mathrm{s}$ is the isothermal compressibility of liquid in $\mathrm{m}^{2} / \mathrm{N}$

$v$ is ratio of specific heats in $\mathrm{m}^{2} / \mathrm{N}$

Relaxation time is related with Debye temperature as ${ }^{9}$

$$
\tau=\left(\mathrm{h} / 2 \pi \theta_{\mathrm{D}} \mathrm{K}_{\beta}\right)
$$

Heat of fusion of liquid can be found as follows ${ }^{9}$

Where,

$$
\mathrm{H}=\ln \left(\tau_{\mathrm{B}} / \tau_{\mathrm{R}}\right) \times \mathrm{KT}
$$

$\tau_{\mathrm{B}}$ is relaxation time at boiling temperature in sec

$\tau_{\mathrm{R}}$ is relaxation time at normal temperature in sec

Sound velocity at boiling temperature is calculated using the relation ${ }^{10-11}$

$$
\mathrm{C}_{\text {gas }}=\mathrm{C}_{\text {liqud }}\left(\mathrm{V}_{\mathrm{f}} / \mathrm{V}\right)^{1 / 3}
$$

Where,

$\mathrm{V}$ is the molar volume of the liquids in $\mathrm{m}^{3}$

$\mathrm{V}_{\mathrm{f}}$ is the free volume in $\mathrm{m}^{3}$

\section{Results and Discussion}

Table 1 gives the values of sound velocities and densities of normal temperature and boiling temperature for 19 organic liquids. By treating liquids on polycrystalline solid ${ }^{9}$, the thermal properties such as relaxation time and Debye temperature of organic liquids are calculated at normal temperature and boiling temperature and presented in Table 2. From Debye's relaxation time, the heat of fusion has been calculated and presented in Table 2.

In all system, densities and velocities at boiling temperature are less than the normal temperature. This is due to free space created between the molecules/atoms by temperature. This is conformed by the value of Debye temperature. The value of debye temperature at boiling point is less than those at normal temperature that is the disorder increases at boiling temperature. 
Table 1. Velocity and density of some organic liquids at normal and boiling temperature

\begin{tabular}{ccccc}
\hline Liquid & $\begin{array}{c}\mathrm{C}_{\text {normal temp, }}^{*} \mathrm{~m} / \mathrm{s} \\
\text { Methanol }\end{array}$ & $\begin{array}{c}\mathrm{C}_{\text {boiling temp, }}^{*} \mathrm{~m} / \mathrm{s} \\
\text { Ethylene glycol }\end{array}$ & $\begin{array}{c}\rho_{\text {normal temp }}, \\
\mathrm{kg} / \mathrm{m}^{3}\end{array}$ & $\begin{array}{c}\rho_{\text {boiling temp }} \\
\mathrm{kg} / \mathrm{m}^{3}\end{array}$ \\
Heptane & 11434 & 0995.378 & 0791 & 0476.450 \\
Glycerine & 1138 & 1175.881 & 1113 & 0814.821 \\
Octane & 1171 & 1178.289 & 1261 & 0368.840 \\
Phenol & 1274 & 0445.229 & 0107 & 383.283 \\
Acetic acid & 1584 & 1419.274 & 1049 & 0102.618 \\
Acetone & 1190 & 1146.275 & 0780 & 0610.129 \\
Chloroform & 0995 & 0898.606 & 1483 & 0811.918 \\
Pentane & 1044 & 1012.982 & 0626 & 0327.941 \\
Ethanol & 1144 & 0976.823 & 0789 & 0486.276 \\
Benzene & 1295 & 1180.358 & 0868 & 0494.181 \\
Toulene & 1275 & 1130.660 & 0867 & 0510.767 \\
Glycerine & 1904 & 1177.848 & 1262 & 1019.516 \\
Butanol & 1228 & 1573.510 & 0809 & 0261.420 \\
Pentanol & 1256 & 1586.372 & 0814 & 0270.015 \\
Methyl propanol & 1110 & 1418.030 & 0802 & 0259.020 \\
Heptanol & 1305 & 1608.090 & 0818 & 0284.912 \\
Propanol & 1190 & 1543.360 & 0803 & 0252.407 \\
Hexanol & 1283 & 1598.780 & 0813 & 0276.686 \\
\hline
\end{tabular}

Table 2. Thermal properties of some organic liquids

\begin{tabular}{cccccc}
\hline Liquid & \multicolumn{2}{c}{ Relaxation time } \\
& $\begin{array}{c}\text { Normal } \\
\text { temp }\end{array}$ & $\begin{array}{c}\text { Boiling } \\
\text { temp }\end{array}$ & $\begin{array}{c}\text { Debye temperature, } \mathrm{K} \\
\text { Normal } \\
\text { temp }\end{array}$ & $\begin{array}{c}\text { Boiling } \\
\text { temp }\end{array}$ & $\begin{array}{c}\text { Heat of fusion, } \\
(\mathrm{Cal} / \mathrm{g})\end{array}$ \\
\hline Methanol & 0.8094 & 1.1005 & 94.45 & 69.47 & 26.86 \\
Acetic acid & 0.1654 & 0.8754 & 116.76 & 87.33 & $72.37(44.07)$ \\
Ethylene glycol & 0.6259 & 0.9722 & 122.14 & 78.64 & 27.72 \\
Chloroform & 1.1679 & 1.5530 & 65.46 & 49.23 & $6.62(19.01)$ \\
Heptane & 1.1264 & 1.6513 & 61.34 & 47.33 & 8.85 \\
Octane & 1.2541 & 1.6321 & 60.94 & 46.82 & 7.65 \\
Phenol & 2.0256 & 5.8901 & 37.75 & 12.97 & 42.93 \\
Acetone & 1.0054 & 1.2910 & 76.19 & 59.37 & 10.11 \\
Pentane & 1.2550 & 1.6060 & 60.91 & 47.59 & 8.75 \\
Ethanol & 1.0950 & 1.2580 & 83.72 & 60.77 & 8.70 \\
Benzene & 0.9315 & 1.2323 & 82.07 & 61.99 & $10.55(30.01)$ \\
Toulene & 1.0000 & 1.3448 & 76.43 & 56.85 & 10.27 \\
Glycerine & 0.5911 & 1.0256 & 129.33 & 74.54 & 19.05 \\
Butanol & 0.9875 & 1.1250 & 77.41 & 67.95 & 4.24 \\
Pentanol & 1.0222 & 1.1695 & 74.79 & 65.37 & 5.22 \\
Methyl propanol & 1.0965 & 1.2495 & 69.72 & 61.18 & 5.58 \\
Heptanol & 1.0770 & 1.2423 & 70.98 & 61.54 & 4.58 \\
Propanol & 0.9538 & 1.0817 & 80.15 & 70.67 & 4.70 \\
Hexanol & 1.0770 & 1.2081 & 72.70 & 63.28 & 4.87 \\
\hline
\end{tabular}


Calculated heat of fusion from Debye's relaxation time throws light on the author's idea. Literature value available is presented in parenthesis ${ }^{12}$. The deviation may be explained after elaborate study.

\section{Conclusions}

From this study, ultrasonic velocity at boiling temperature, values of thermal properties like Debye's temperature and relaxation time at normal and boiling temperature are expected range, that is Debye temperature at normal temperature $>$ boiling temperature and relaxation time at normal temperature < boiling temperature. Another thermal property, heat of fusion from thermal relaxation time is a fresh attempt for organic liquids. Values of heat of fusion support new approach.

\section{References}

1. Suryanarayana C V, Indian J Chem., 1986, 25A, 538.

2. Barnat S, J Chem Phys., 1952, 20, 278.

3. Rama Rao, Curr Sci., 1954, 23, 325.

4. Durai S and Ramadoss P, J Pure Appl Ultrason., 2006, 28, 1.

5. Palani. R and Jaya chitra. K, Indian J Pure Appl Phys., 2008, 46, 251.

6. Rajagopal K and Edwin Gladson S, J Pure Appl Ultrason., 2006, 28, 87.

7. Ramadoss.P. Proceedings XVIII National Symposium on Ultrasonics, 21-23 Dec 2009, 537.

8. $\quad$ Kor.S.K and Tripathi N D, J Phys Soc Japan, 1967, 23, 476

9. Frenkel J, Kinetic Theory of Liquids, Oxford University Press Newyork, 1946.

10. Kittel C, J Chem Phys., 1946, 14, 614.

11. Tonks L, Phys Rev., 1936, 50, 955.

12. Kaye G W C and Laby T H, Physical and Chemical Constants and Some Mathematical Functions, $13^{\text {th }}$ Ed, Longmans, Green \& Co Ltd, London, 1966. 


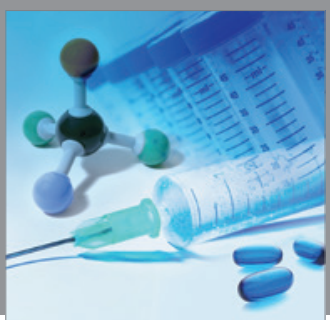

International Journal of

Medicinal Chemistry

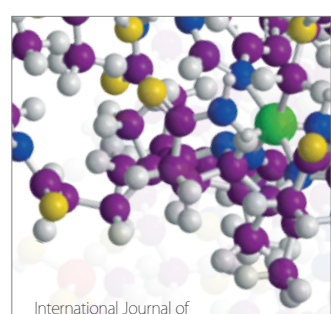

Carbohydrate Chemistry

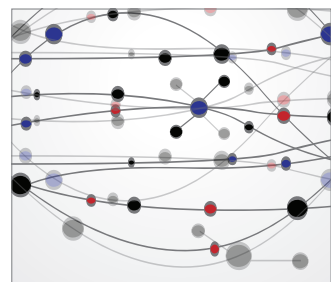

The Scientific World Journal
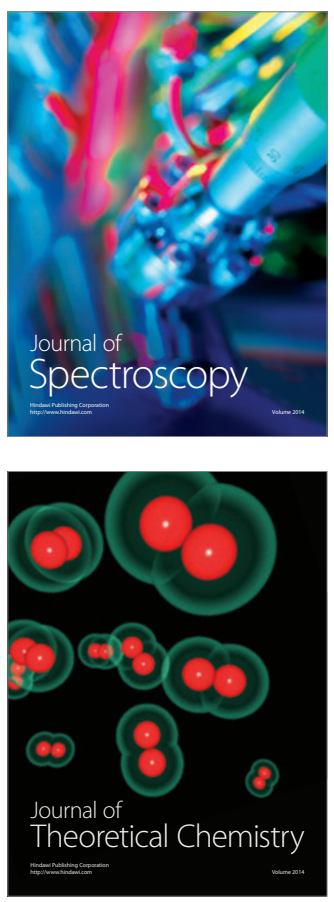
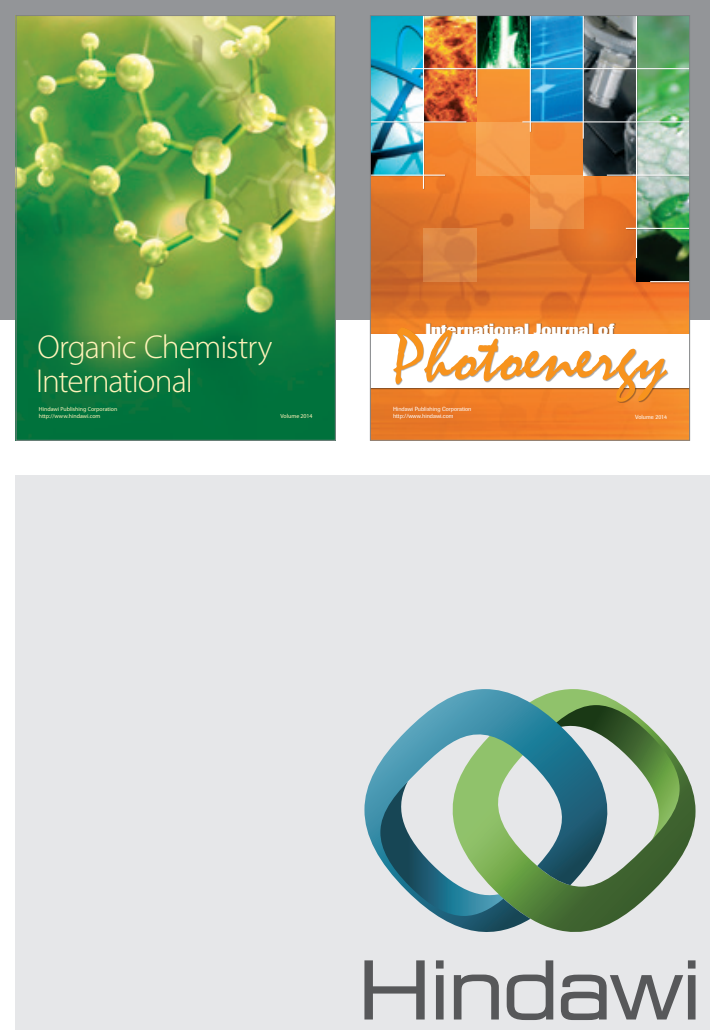

Submit your manuscripts at

http://www.hindawi.com
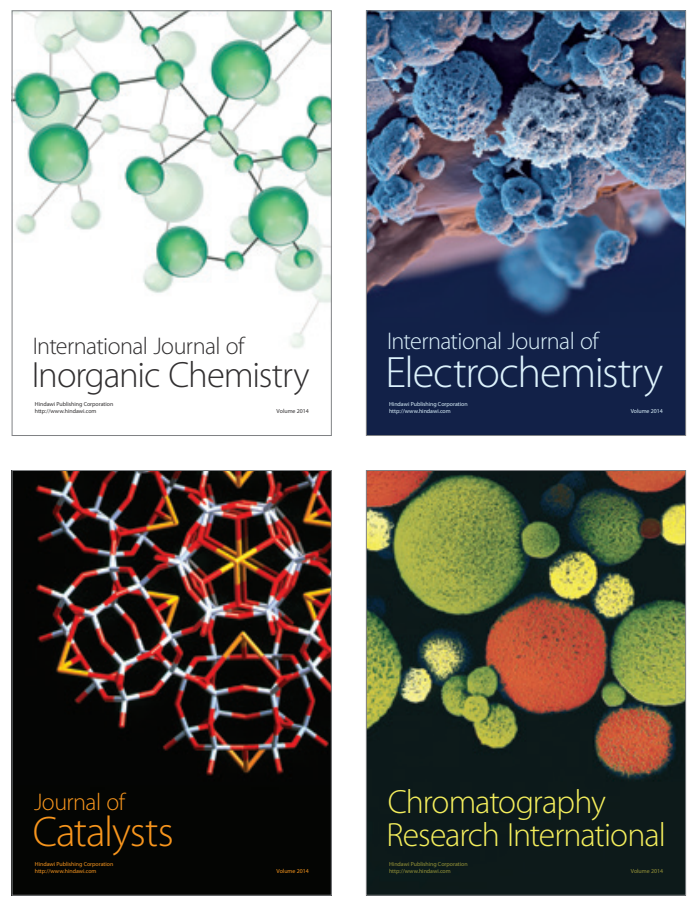
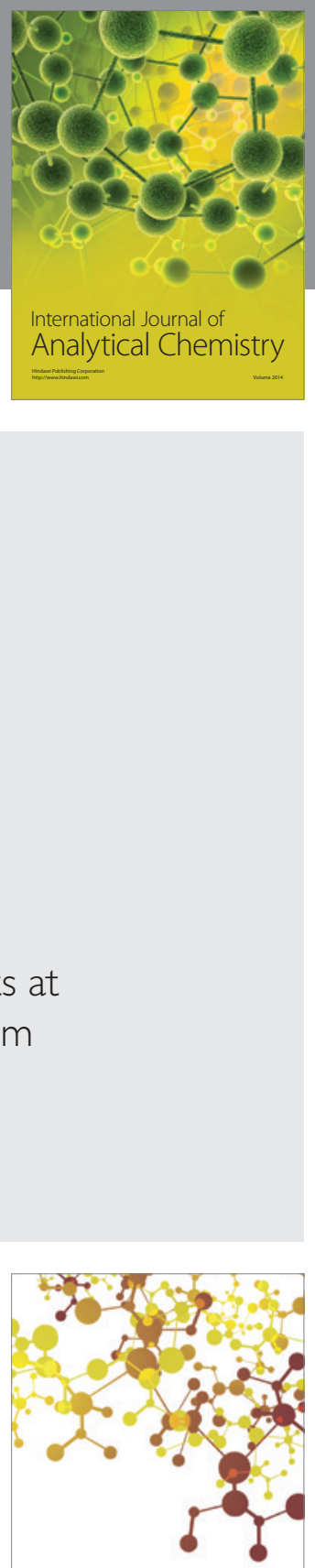

Journal of

Applied Chemistry
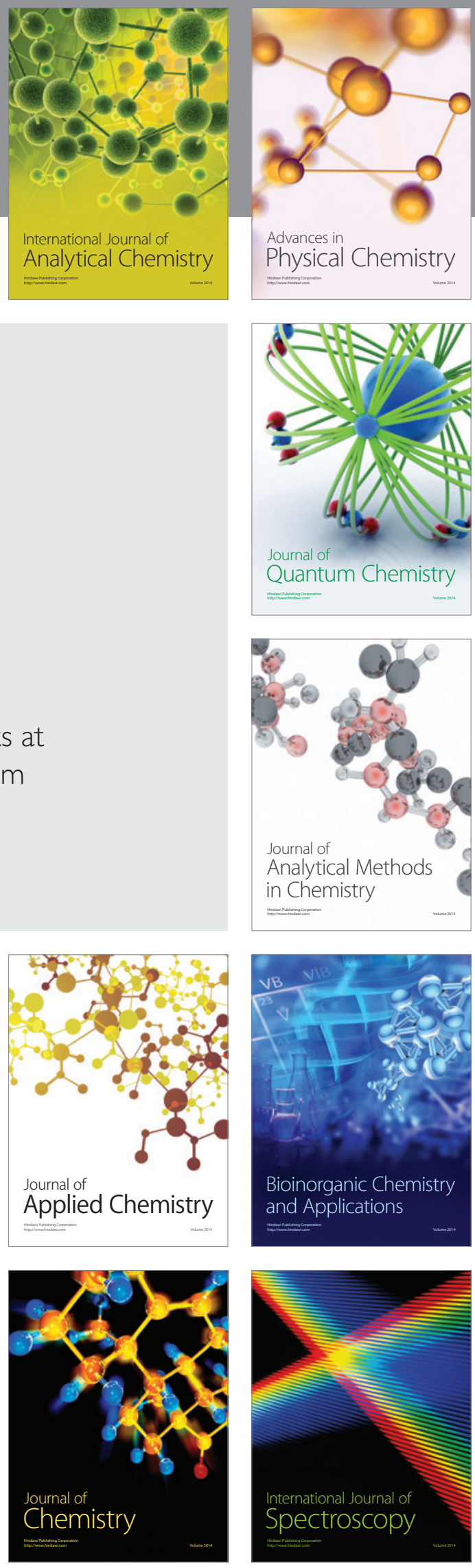